Asheena Singh-Pillay*

${ }^{*}$ Corresponding author. School of Education, University

of KwaZulu-Natal, Private

Bag X03, Ashwood, 3605,

South Africa.

Email: Pillaya5@ukzn.ac.za

Frank Ohemeng-Appiah

School of Education, University

of KwaZulu-Natal, South Africa

DOI: $h$ ttp://dx.doi.

org/10.18820/2519593X/pie.

v34i2. 6

ISSN 0258-2236

e-ISSN 2519-593X

Perspectives in Education

2016 34(2): 70-82

(c) UVIUFS

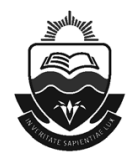

\section{Interconnectedness of technology teachers' perceptions of the design process to learner creativity}

\begin{abstract}
The design process (DP) is key to technology education and is considered as synonymous with problem solving, hence it undergirds all its learning aims and objectives. The Curriculum Assessment and Policy Statement (CAPS) document envisages that the design process will promote problem solving, critical thinking and creativity in learners. However, a paucity of empirical studies within the South African context illuminates the interconnectedness of DP to problem solving, critical thinking and creativity in learners for which the CAPS policy advocates. Further, there is a need to explore the interconnectedness of teachers' perceptions of the DP, their enactment of the DP and its impact on learner creativity. This paper reports on a study that explored that interconnectedness and addressed the following research questions: What are grade 9 technology teachers' perceptions of the design process? How do these perceptions relate to teachers' reported enactment of the $D P$ and creativity in learners? The conceptual framework used to model the interconnectedness that exists between teachers' perceptions and reported enactment of the design process is Shulman's pedagogical content knowledge model (PCK). This interpretivist study was located in the Umlazi district of KwaZuluNatal. A case study design was used to collect qualitative data via an open-ended questionnaire and a semi-structured interview from 30 purposively selected technology teachers. Content analysis of data was undertaken in line with the conceptual framework. Our findings reflect that teachers' perception and reported enactment of $D P$ and the flexibility of the learning environment have an impact on opportunities for problem solving, critical thinking and creativity in learners. Our findings raise questions about the type of professional development teachers need to enact the envisaged goals of the CAPS document in respect of the DP in technology education.
\end{abstract}

Keywords: Design process; enactment of the DP; learner creativity; pedagogical content knowledge; teachers' perception of the $D P$

\section{Introduction}

It is well established by scholars such as Gustafson and Rowell (1998), Hill (1998), Lewis (2006), Pudi (2007) and Kangas, Seitamaa-Hakkarainen and Hakkarainen, (2011) that problem-solving, critical thinking and creativity skills are key aspects of the design process in technology education. These skills are considered crucial for innovation and finding solutions to problems (Vandeleur et al., 2001). The 
design process in technology education is construed as a vehicle through which dimensions of learners' creative abilities can be stimulated and augmented (Lewis, 2006; Mapotse, 2014). From the foregoing points, it makes sense that the problem solving process in the DP is intertwined with critical thinking and creativity. Stimulating creative impulses in learners through design and problem-solving activities is a central goal of the senior phase technology grades 7-9: Curriculum Assessment and Policy Statement (CAPS) document, (DBE, 2011). As such, the design process ought to be used to structure and drive the delivery of all learning aims of the technology subject in South African schools (Mabaso, 2014). For learners of technology education to be able to develop the aforementioned capabilities and skills, they need to engage with the design process whereby they are provided with opportunities to create solutions to problems in new and innovative ways.

Development of the above-mentioned skills hinges on teachers of the technology subject. According to Tholo, Monobe and Lumadi (2011), the successful implementation of the technology curriculum is dependent on teachers having the same set of skills and theoretical understanding that the curriculum requires from learners. With regard to the preceding point, it is worth noting that Pudi (2007) asserts that the implementation of the design process in technology education within the school curriculum has been a hurdle for teachers.

Since the introduction of technology education into the South African school curriculum, teachers have experienced the following policies, Curriculum 2005 (C2005), Revised National Curriculum Statement (RNCS) and now CAPS. Teachers are still grappling with the pedagogy and didactics of CAPS (Ohemeng-Appiah, 2014). In addition to teachers' dilemmas about their conceptualisation and enactment of the design process it must be noted that there has been a (re)-presentation of the design process from linear (in RNCS) to a non-linear (re)presentation (in CAPS) (DBE, 2011). The (re)-presentation of the design process influences the flexibility of its enactment and opportunities for learner creativity. This article, therefore, addresses the following questions: What are grade 9 technology teachers' perceptions of the design process? How do these perceptions relate to their reported enactment of the design process $(D P)$ and learner creativity?

\section{Literature review}

A survey of literature shows that problem solving, critical thinking and creativity are intrinsically intertwined with the DP (Friesen, Taylor \& Britton, 2005). Asunda (2007) perceives design as a structured process that transforms creative ideas into concrete products, services and systems and as such, links creativity to innovation. Creative thinking produces novel outcomes and problem solving produces a new response to a situation, which is a novel outcome. Therefore, problem solving has creative aspects. According to Vandeleur et al. (2001), Asunda (2007), Davis (2011) and Wakefield (1992), some of the key indicators of creativity during the DP are freedom to generate ideas, flexible use of space and time, availability of appropriate materials, room for experimentation, non-conformity, justification of choices and ability to see a solution. Other indicators of creativity include the generation of new problems, the relationship between teacher and learner and opportunities for collaboration with peers. The flexibility of the DP enactment influences learner creativity, problem solving and critical thinking.

Literature on DP reveals there are two views in respect of how the design process should unfold. On the one hand, the design process is perceived as a systematic or linear productbased process aimed at meeting the requirements of assessment, whilst on the other hand, 
it is considered as a creative, problem solving, iterative and cyclical process reliant on multidisciplinary knowledge. Williams (2000) and Mawson (2003) assert that a common view amongst teachers is the understanding of the DP as a product-based or a linear process. This means, the DP is construed as a series of steps that are outlined by the teachers, namely, identify-design-make-appraise. Learners are expected to follow these steps sequentially and diligently in their projects. In the linear approach, the emphasis is on the product and not the processes involved in producing the product. The foregoing approach of the DP is highly prescriptive, propagates conformity and does not provide enough room for novelty and imagination, does not stimulate learners to generate multiple original ideas for developing the problem solving, critical thinking or creative skills required of them (Lewis, 2006) and does not allow for learner autonomy (Rowel, 2004). The ideology behind this systematic process, Williams (2000) argues, is that it can be taught. This rigid procedure is inviting to teachers because it provides a structure for the teaching of technology. Flower (2010: 16) contends that one should not lose sight of the fact that "we are not there for learner or teacher comfort". Furthermore, a focus on "steps" in the teaching of design may be the crutch that teachers cling to because of the tension between their view of the DP and the pedagogy they use to facilitate the DP.

The seemingly rigid nature of the identify-design-make-appraise model of the DP calls for an alternative pedagogy or approach. Hill (1998) directs our attention to the disparity between the DP employed in problem solving in real life contexts by engineers and that which is found in the classroom. As she puts it,

In problem solving for real-life contexts, design processes are seen as creative, dynamic and iterative processes that engage exploration; join conceptual and procedural knowledge-both thought and action; and can encourage considerations to technology, human and environmental interactions (Hill, 1998: 203).

This means the complexity of the DP stems from its cyclical and iterative nature and that possible solutions come from a complex interaction between parallel refinements of the design problem and ever-changing design ideas. The approach suggested by Hill (1998) is antithetical to what is typically found in schools: design, make and appraise cycles based on closed design briefs that are teacher-assigned, which incidentally are unrelated to the learners' worlds.

Research by Bailey (2012) and Atkinson (2011) have shown that teachers of design and technology do not have what it takes to help learners in this regard. In agreement, Pool, Reitsma and Mentz (2013) argue that technology teachers in South Africa lack the appropriate subject specific pedagogical content knowledge (PCK; Shulman, 1986) to teach technology and the DP, which happens to be the backbone of technology education. Lewis (2006: 263) therefore highlights the need for pedagogic strategies that can stimulate the inventive urges of children to bring about "problem solving, divergent thinking, combination, metaphorical thinking, and analogical thinking when engaging in the design process".

\section{Conceptual framework}

Kuhn (1996) posits that professional practice is underpinned and shaped by a received set of beliefs, values, views and models. In agreement, Wenglinsky (2002) suggests that what a teacher does in class depends on the teacher's knowledge and the class context. With the above in mind, the constructivist epistemology and Shulman's pedagogical content knowledge model (PCK) (1986) have been used to frame the research. According to Shulman, 
PCK refers to the transformation of content into a form that makes or promotes learning possibilities; it is the intersection of content knowledge (CK) and pedagogical knowledge (PK) specific to a subject and its content area. PK is a teacher's orientation towards teaching. In this study, it refers to teachers' beliefs about the nature, purposes and goals for teaching and learning technology at different grade levels. These particular beliefs serve as a concept map that guides instructional decisions, the use of particular curricular materials and instructional strategies and assessment of learners' learning. This includes being flexible and adjusting instruction to account for various learning styles, creativity, learner autonomy, abilities and interests. Knowing how best to teach a concept so that the learners will receive the best learning experience, speaks to the essence of PCK. Shulman's PCK model is generic and hence needed to be adapted in order to depict what PCK looks like when applied to technology education, in particular to the design process. The authors have developed figure 1 below as a way to reflect the major aspects of PCK as applied to the design process.

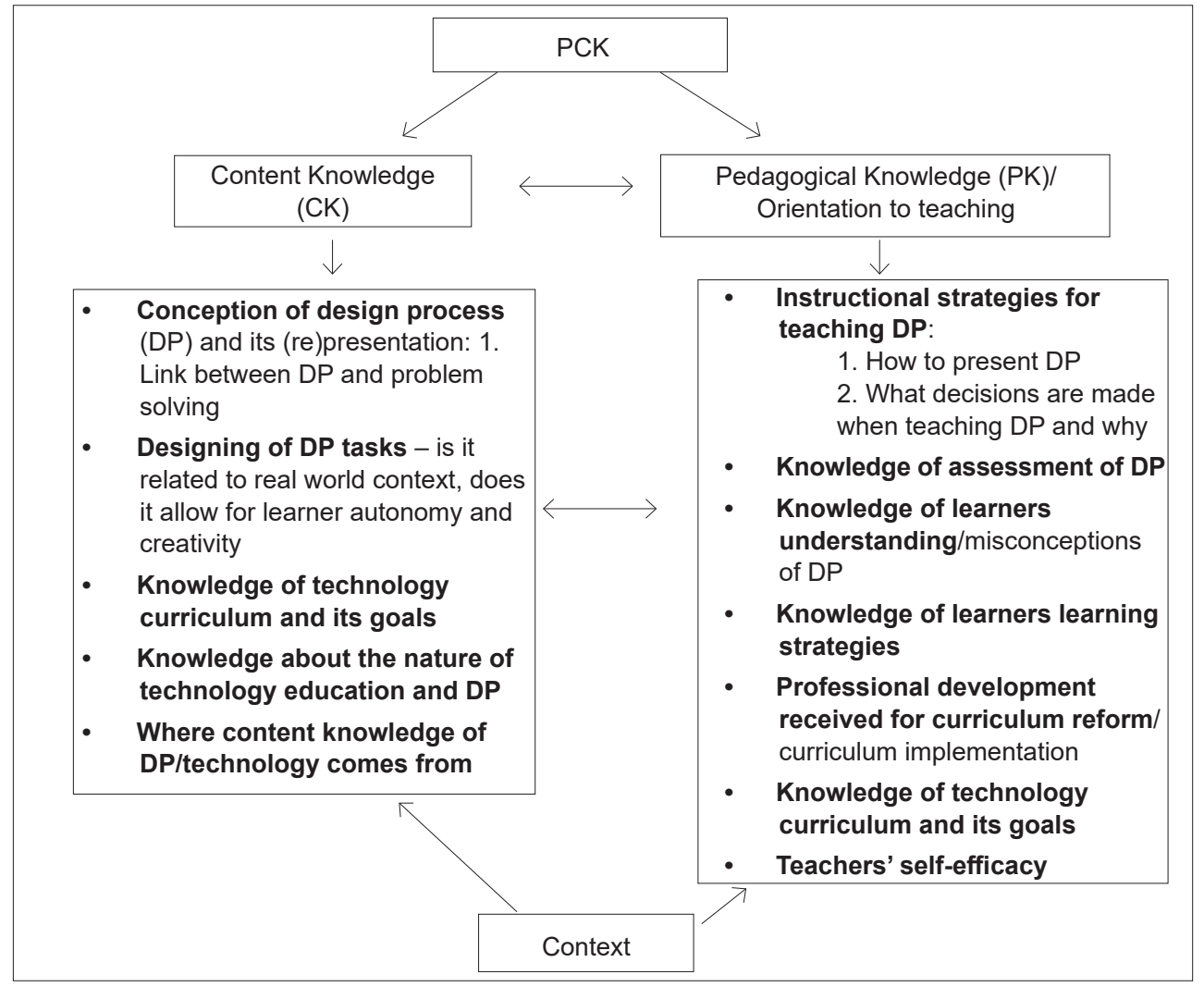

Figure 1: Singh-Pillay and Ohemeng-Appiah proposed model of PCK as applied to the design process

We posit there is a relational interplay between CK, PK and context as context frames if it is possible for teachers to understand the problem solving, critical thinking and creativity associated with DP and successfully guide learners in the DP to generate creative output. CK foregrounds five components, namely knowledge of the technology curriculum and its goals, knowledge about the nature of technology education and the DP, conception of DP, design 
of the DP tasks and understanding of where content knowledge of the DP/technology comes from. These five components are considered important as they promote deep conceptual understanding of the DP. PK consists of six components, namely, instructional strategies for teaching the DP, knowledge of assessment of the DP, knowledge of learners' understanding, knowledge of learners' learning strategies, professional development received, teacher selfefficacy and knowledge of the technology curriculum and its goals. In the above model, the component knowledge of the technology curriculum is significant to $\mathrm{CK}$ and $\mathrm{PK}$, it bridges the divide between $\mathrm{CK}$ and $\mathrm{PK}$ and it facilitates the reciprocal interplay between $\mathrm{CK}$ and $\mathrm{PK}$ to promote learner problem solving, critical thinking and creativity during the DP. Knowledge of the technology curriculum and its goals enables teachers to identify core concepts, modify activities/tasks, adjust teaching and assessment strategies, promote self-efficacy, become contextualised curriculum developers at their schools and eliminate aspects judged peripheral to the targeted conceptual understandings. Knowledge of the curriculum is significant as it brings to the fore the tension between covering the curriculum for exam or assessment purposes and teaching for the promotion of critical thinking, creativity and problem solving.

The rationale for the use of the above PCK framework in data analysis is that it enables understanding of teachers' perceptions of the DP, as their perceptions will touch on the content knowledge related to the DP (CK) or to their understanding of ways of teaching the DP (PK) or the interplay between the two. Therefore, it is imperative to know the PCK of the teacher as such knowledge shapes his/her perceptions regarding the design process and will subsequently impact his/her enactment of the DP and opportunities for learner critical thinking and creativity.

\section{Methodology}

This study is located in the Umlazi district (UD) in KwaZulu-Natal and represents a qualitative case study of this district. There are 30 high schools in the district and each school has a minimum of one technology teacher. Teachers were purposively selected, the criteria for their selection was that they had to be teaching grade 9 technology. According to Maxwell (1998: 122), "this is a strategy in which particular settings, persons, or events are deliberately selected for the important information they can provide that cannot be gotten as well from other choices". In instances where schools had two grade 9 teachers, the teacher with the highest grade 9 workload was selected. Formal permission to conduct research was obtained from the University of KwaZulu-Natal's research office and the KZN Department of Education to conduct this study at 30 schools (HSS/0622/014M).

Data was collected in two phases. During phase one, 30 teachers answered an open-ended questionnaire, which was designed with the assistance of university researchers to foreground the components of the PCK framework developed for the DP (see figure 1). The questionnaire was piloted with 20 grade 9 teachers of technology from ward 134 in the Pinetown District, as they closely resemble the target population of technology teachers in terms of the grade they teach and the type of professional development they received for the implementation of the CAPS curriculum. In addition, these teachers would be able to identify questions that were ambiguous, had difficult wording or problems with the questionnaire that might lead to biased answers. The questionnaire comprised two sections. The first section targeted biographical data in terms of qualification, teaching experience, subjects taught, professional development received to teach technology and knowledge of the technology curriculum and its content. The second section gathered information on teachers' perceptions and understanding of the design 
process, what does DP entail, the role of the DP in learner problem solving abilities, critical thinking, creativity and autonomy during the DP and the importance of the design process in teaching technology. This section also gathered information on the planning they undertook to teach the DP, aspects of the design process that are emphasised during teaching, how the DP is assessed, emphasis placed on learner creativity during the DP and training received for curricula reform in technology. The information obtained from the questionnaire was used to map the grade 9 technology education topography, within the Umlazi District, in terms of teachers' perceptions of the design process and how these perceptions impact their reported enactment of the DP and learner creativity.

For phase two of data collection, video-recorded semi-structured interviews were conducted with the initial sample from stage one. The semi-structured interviews aimed to probe teachers' responses from the questionnaire and establish what influence teachers' perceptions of the DP have on the enactment of the DP and learner creativity. The video recordings were first transcribed verbatim and then subjected to denaturalised transcriptions. In denaturalised transcriptions, the written text is devoid of "ums and errs" and commas and full stops are added to aid readability and to adhere to issues of participant confidentiality and anonymity (Duranti, 2007). To ensure the validity of data, the transcripts were sent to the teachers for member checking to verify if the text was an accurate (re)-presentation of what was stated during the interviews.

Data collated via the questionnaire and semi-structured interview was deductively content analysed. Data was read and then coded using the elements of our PCK framework (see figure 1 for component of CK and PK). The goal of content analysis is "to provide knowledge and understanding of the phenomenon under study" (Downe-Wamboldt, 1992: 314). Codes were (re)examined to form four categories on the conceptions of DP, teaching and assessment strategies used, teacher qualification/training received and links between teaching strategy and learner creativity. The four categories were integrated to arrive at two themes: teachers' perceptions of DP and their reported enactment of DP. In using this approach, all the relevant data from data sources (questionnaires and interviews) were collated to provide a collective answer to the research questions. This was in line with the explanation given by Cohen et al. (2011) that qualitative data involves organising, accounting for and explaining the data in terms of the participant's conception of the phenomenon being explored, noting patterns, themes, categories and regularities.

\section{Presentation of results and discussion}

In this section, we present our results and discussion under two themes:

- Perceptions of the DP

- Perceptions of enacting DP and promotion of learner creativity through the DP

\section{Perceptions of the DP}

Data from the questionnaire reveal that there are two perceptions of the DP, namely

- DP is the backbone of technology education

- DP entails problem solving 


\section{$D P$ is the backbone of technology education}

All 30 teachers saw the DP as the core activity in technology education as is illustrated in the excerpts below:

T13: Design is to technology what the backbone is to humans it supports everything

T7: It is the spine of technology and foundation for all tech lessons

T18: It is the backbone of technology education

T29: It is the central canal of technology education

The above findings illuminate these teachers' CK on the nature of technology education and their awareness of the goals of technology education as per the CAPS policy (DBE, 2011). Based on their above perception on the importance of the DP during the structuring of teaching and learning activities, the expectation is their CK and awareness of the DP (the backbone of technology) will inform and guide their teaching and learning orientation (PK) towards problem solving, critical thinking and creativity (foundation for all tech lessons).

\section{DP entails problem solving}

Additionally, all 30 teachers construed the DP as a problem-solving activity, as reflected in the excerpts below:

T1: The design process entails problem solving

T25: It is supposed to promote problem solving and critical thinking in learner

T17: Learners are to be creative in their solutions to the posed problem

T29: $D P=$ problem solving, deep thinking + creativity

The above excerpts point to these teachers' reported CK on the DP (entails problem solving). They all associated the DP with problem solving and construed the DP as an avenue to nurture problem solving, critical thinking and creativity in learners ( $D P=$ problem solving, deep thinking + creativity). They explicitly link DP to problem solving, critical thinking and creativity (promote problem solving... critical thinking... creative in their solutions). The logical anticipation is that their $\mathrm{CK}$ will be the conceptual map that they will use to align their instructional strategies (PK) and activities pertaining to the DP to promote learner creativity. The above finding warranted further probing during the semi-structured interviews to establish their reported perceptions of their enactment of the DP.

\section{Reported perceptions of enacting the DP and promotion of learner creativity through the DP}

The data obtained via the semi-structured interviews illuminates that teachers hold two divergent views on the DP even though they all construe the DP as a backbone to technology education and a problem-solving activity, namely:

- Design process as cyclical/iterative

- Design as a step-by-step process that provides "comfort" to learners during problem-solving

\section{Design process as cyclical}

Nine of the 30 participants viewed the design process as being cyclical or iterative as reflected in the excerpts below: 
T5: Technology is the only subject I teach. I devote a lot of energy in designing activities that allow learners to solve problems, my class is learner-centred...developing original ideas allow for creative designs and solutions from learner ...they skip stage, work simultaneously, discuss with peers, on refining ideas, design and the product, the aim is to get learner to think outside a box, it is rewarding to see some of the original idea, there are features of creativity you can look for, novelty of idea, persistence, not giving up when the first solution fails, ability to justify your absurd solution, making adjustments, vision.

T15: It's a cyclic process, to solve problems, learners must be given the chance to think and come up with many novel ideas to solve problem in their context, their many ideas requires them to think deeply to work towards possible solutions, I prepare well to contextualise the design activities so learners can see the link to design and everyday life, fortunately resources are readily available for me to teach technology, creativity entail uniqueness of the idea, depth of think, determining dimensions, thinking and visualising $3 D$ and $2 D$, communicating graphically. How are we going to produce engineers if we curb visual creativity?

T8: DP is all about problem solving, I enjoy teaching technology, I believe less is more, I allow learner a lot of freedom to experiment, think about the solutions, I create a positive environment, sometimes a child may have one of the better solutions which I as a teacher would not have thought about. They are doing projects on their own, they are free to discuss with their friends, they take control of the process, some of them come up with really good examples.

The above excerpts illustrate the rational interplay first between these teachers' reported perception of the DP as problem solving and cyclical (their CK) and their teaching strategy when they engage in the DP (PK). Secondly, the interplay between their teaching strategy (PK - including their knowledge of the nature of technology education, the technology curriculum, its goals, knowledge of assessment of DP and knowledge of learners' learning strategies) and learner creativity comes to the fore. This means that their CK of the DP maps their PK and directs the opportunities created for learner critical thinking and creativity. In a subtle way, the aforementioned relational interplay allows us to see how, via their PK, these teachers create opportunities for nurturing learner creativity in their classrooms by allowing learners cognitive freedom, for problem solving and critical thinking (think deeply, think outside a box, think about solutions). For these teachers, the DP is not reduced to a "cookbook recipe" whereby learners follow the steps of the DP in a rigid sequential fashion (work simultaneously on refining ideas, design and the product). Rather, it is an iterative process involving back and forth movement between stages (skip stages) to refine ideas (thinking) and the final product.

The above excerpts highlight the complexity of the DP that arises from its cyclical and iterative nature. Where possible, solutions come from a complex interaction between parallel refinements of the design problem and ever-changing design ideas (Hill, 1998). Furthermore, these findings clearly show that these respondents' reported perception of DP (namely their $\mathrm{CK}$ ) guides them to be flexible in their instructional strategies (namely their PK) pertaining to the DP as well as the design of the DP tasks (contextualise). These respondents' learnercentred classroom creates the space for learners to practise and learn to be creative by engaging in problem solving and critical thinking. These teachers are aware of their learners and their learning strategies (must be given a chance, solve problem in their context, contextualise) consequently they provide opportunities for learners to apply their knowledge to solve everyday problems. Hence, their learners are given a chance to take control of the "learning" during the design process (they are doing the project on their own; create your own design), be creative (novel) and engage in critical thinking (think deeply, discuss with friends) 
and problem solving. These teachers' reported enactment of DP enables and fosters problem solving, critical thinking and creativity in learners during the DP (generation of novel ideas, deep thinking, persistence, not giving up when the first solution fails, thinking and visualising $3 D$ and $2 D$ ). For these teachers, there are multiple solutions to any problem and multiple ways to work towards solutions for the identified problem.

The preceding finding raises our attention to the interwoven link between teachers' CK, $\mathrm{PK}$, the effective use of their pedagogical space and its impact on learner creativity during the DP. The above excerpts bring to the fore indicators for creativity that are embraced by these teachers in their engagement of DP (PK). These include freedom to generate ideas, availability of resources, room for experimentation, relationship between teacher and learner (freedom to experiment, learner-centred, they take control, contextualise the problem), opportunities to collaborate with peers (discuss with peers) and being well prepared (devote a lot of energy in designing activities, create a positive environment). The above findings elucidate the intricate link between teachers' perception of the DP (CK), their reported enactment of the DP (PK) and how the DP can be used to foster learner creativity.

\section{Design process is a systematic process that provides comfort to learners during problem solving}

An interesting finding that presented itself within the data collated from the interview was that the majority of teachers (21 of the 30 ), who earlier considered the design process as a problem solving activity (via the questionnaire), conceived the design process as a systematic process as represented in the excerpts below.

T9: It is not easy to teach DP I can only teach design process if I follow the steps, how am I teach it if there are no stages to follow, that is so hard, how can I assess the end product if they are different, I will be assessing forever, what must I look for... I need help to learn to teach DP, hey the training we get at workshops is useless, I didn't train to teach tech.

T21: It is easier to teach the design process... in a step-by-step manner because all the products are the same, the solutions are the same, the assessment becomes easy and is completed faster. I also teach another learning area in the FET phase, so I don't pay too much attention to technology as it is my filler subject.

T12: I don't like teaching DP, in fact I'm not a qualified technology teacher, technology is hard to teach compared to social studies and EMS, I use the step by step way to have control in class so I can do something with the learners and then I assess the product, all I want is a product, I'm not interested in their thinking or creativity or who makes the product.

T6: I teach DP in a step by step way, my teaching is very structured, all the learners need to follow the same steps at the same time, reach the same solution, I guide them all the way, there is no room for learners to be creative, or to discuss with peers, they can be creative in arts and culture, there is too much marking, I teach three learning areas, so I want the end product that are the same and easy to assess. They all pass no one fails technology.

The incongruence between these teachers' perceptions of the DP (CK) and reported enactment of the DP is illuminated via the above excerpts. The incongruence raises questions about these teachers' knowledge of the DP, how they construe the link between the DP, problem solving, critical thinking and creativity, where their CK of the DP comes from (not a qualified technology teacher...filler subject) and how they teach the DP. The interplay between 
these respondents' reported perceptions of the DP as a rigid step-by-step process (their CK), their reported teaching of the DP (their PK), their preoccupation with the assessment of an end product and the contextual factors that sculpt their pedagogical space and impact learner creativity all comes to the fore via the above excerpts.

These teachers' CK of the DP is congruent with their enactment (PK) of the DP. Their perception of the DP (CK) as a rigid, foreseeable process that unfolds in a particular sequence (you identify, define....and solve the problem, reach the same solution), directs their classroom practice pertaining to the DP (have control, teach DP in a step by step way, my teaching is very structured) and impinges learners' opportunities for problem solving, critical thinking and creativity (end products ...solutions are the same). During their teaching of the DP, much emphasis is placed on the production of a product (all I want is a product), rather than the processes involved in the production of the product such as problem solving and creative thinking (not interested in their thinking or creativity). Their linear perception of the DP undermines the individuality of learners (end products that are the same). Furthermore, it deprives learners of the opportunity to engage in creativity as all learners are directed towards a particular solution (the solutions are the same). Their inflexible enactment of DP stifles opportunities for learner critical thinking, as a result learner creativity is suppressed. The above excerpts highlight the unresolved tension between these teachers' PK, their conception of DP, and knowledge of the technology curriculum and its goals. Therefore, their formulaic "step-by-step" idea of "problem solving" does not afford learners the opportunity to be imaginative, think divergently or exercise their voices and ideas in a structured pedagogical space. Their perception of the DP confirms the teacher-centeredness of their classrooms and the lack of learner autonomy. In addition, the linear view of the DP deprives learners of the opportunity to take control of their designs, engage in critical/creative thinking in order to generate novel ideas. Scholars such as Hill (1998), Williams (2000), Mawson (2003) and Rowel (2004) argue that the seemingly rigid nature of the DP does not provide enough room for developing the creative skills of the learner and have suggested the need for an alternative pedagogy or approach.

A closer examination of the above excerpts shows that teaching the DP as a systematic process is a coping mechanism and safety net for teachers rather than their learners as teachers' PCK is not grounded in technology education (filler subject, didn't train to teach tech, teach three learning areas). The rigid structure provided by the systematic process offers teachers some sort of security framework or comfort within which to work when dealing with the uncertainty about CK and PK in technology education and coping with the contextual factors that influence their pedagogical space (teach other learning areas, training is useless, I need help). The lack of appropriate training for the enactment of the DP raises the following questions: How can teachers be flexible in their presentation and assessment of the DP if they lack the required CK and PK? How can teachers be "trained" to engage with and enact DP in a way that promotes learner creativity. Our above finding concurs with the findings of Pool et al. (2013) who argue that in spite of the many workshops conducted on the implementation of the various technology curricula, teachers still lack the appropriate subject-specific PCK to teach technology and the DP. The above finding raises deep concerns about the quality of the training provided to teachers for curriculum implementation. With regard to the preceding point, Lewis (2009: 36) highlights the need for pedagogic strategies that can stimulate the creative urges of children to bring about "problem solving, divergent thinking combination, metaphorical thinking, and analogical thinking when engaging in the design process". 


\section{Conclusion}

Our findings show that teachers' enactment of the DP (their PK) and opportunities for learner creativity hinges on their perceptions of the DP (CK). In other words, teachers' perception of DP influences their PK of DP and opportunities to foster learner creativity. The findings highlight that despite the majority of grade 9 technology teachers' initial perception of the DP as problem solving, their reported enactment of the DP as a systematic process and their incessant preoccupation with the identify-design-make-appraise model of the DP hinder and impinge their PK. The opportunities available to learners for critical thinking, problem solving and creativity are also hindered and impinged by this preoccupation. It is evident from our findings that learner creativity was nurtured by teachers who construed their enactment of DP as problem solving and cyclical as it allowed for cognitive flexibility. This means, their enactment of DP allows learners to take control of their learning, have freedom to experiment, to find solutions and to collaborate with peers. Thus, the pedagogical space created can enhance or inhibit opportunities for learner critical thinking and creativity. Some common features that seem to promote learner creativity are teacher flexibility, teachers' CK, teachers' PK and teachers' attitude to modelling a creative learning environment. Put simply, this means that an enabling environment has to be fostered by the teacher in order to nurture learner creativity. Therefore, CK, PK and the pedagogical space may serve as catalysts for learner creativity. If learners are to be creative problem solvers, then teachers must be creative facilitators during the DP. This means that, being creative in teaching is vital if we are serious about using DP to influence problem solving, critical thinking and learner creativity. There is a delicate intrinsically intertwined link between teachers' CK of the DP, PK pertaining to the DP and the effective use of their pedagogical space to influence problem solving, critical thinking and learner creativity.

Our argument is that teachers' perception of the DP has a direct bearing on their teaching of the DP and on opportunities for learner critical thinking, problem solving and creativity. Howard-Jones (2002) advances the preceding argument, postulating that problem solving, which entails critical thinking and creativity, depends on how the problem solver represents and perceives the problem. The confounding question is, "how do we provide support to technology teachers as well as pre-service teachers of technology to focus on the process of creative skills development rather than on a product during their enactment of DP?"

\section{Implications}

The findings of this case study direct our attention to the need for a professional development programme as an intervention that capacitates teachers of technology, pre-service teachers of technology and teacher educators of technology to model creative attitudes towards teaching the DP. The purpose of the programme should be two fold. First, the programme should provide support to improve participants' PCK in respect of the DP. Second, the programme should initiate a community of practice amongst teachers of technology to share resources (human and physical), study their own practices and talk about them, identifying strengths and weakness. Further, research is needed to explore the link between effective, creative teaching approaches and learner creativity.

\section{References}

Asunda, P. 2007. A multisite case study of faculty and teacher perceptions of NCETE

$P D$. Available at http://ncete.org/flash/research/Multisite_Case_Study.pd [Accessed 9 February 2015]. 
Atkinson, S. 2011. Perspectives on learning in design \& technology education. Paper presented at the PATT25:CRIPT 8 Conference, London.

Bailey, P. 2012. Technology education in the 21st century. Paper presented at the PATT 26 Conference, Stockholm, Sweden.

Cohen, L., Manion, L. \& Morrison, K. 2011. Research methods in education. London: Routledge Falmer.

Davis, D. 2011. Teaching science creatively. London: Routledge.

Department of Basic Education. 2011. National curriculum statement: Continous assessment policy statement (CAPS). Pretoria: Government Printing Works.

Downe-Wamboldt, B. 1992. Content analysis: Method, applications and issues. Health Care for Women International, 13, 313- 321. http://dx.doi.org/10.1080/07399339209516006

Duranti, A. 2007. Transcripts, like shadows on a wall. Mind, Culture and Activity, 13(4), 301-310. http://dx.doi.org/10.1207/s15327884mca1304_3

Flowers, J. 2010. The problem in technology education (A definite article). Journal of Technology Education, 21( 2), 10-20. http://dx.doi.org/10.21061/jte.v21i2.a.2

Friesen, M., Taylor, K. \& Britton, M. 2005. A qualitative study of a course trilogy in biosystems engineering design. Journal of Engineering Education, 94(3), 287-297. http://dx.doi. org/10.1002/j.2168-9830.2005.tb00853.x

Gustafson, B. \& Rowell, P. 1998. Elementary children's technological problem solving: Selecting an initial course of action. Research in Science \& Technological Education, 16(2), 151-163. http://dx.doi.org/10.1080/0263514980160205

Hill, A. 1998. Problem solving in real-life contexts: An alternative for design in technology education. International Journal of Technology and Design Education, 8, 203-220. http:// dx.doi.org/10.1023/A:1008854926028

Howard-Jones, P.A. 2002. A dual-state model of creative cognition for supporting strategies that foster creativity in the classroom. International Journal of Technology and Design Education, 12, 215-226. http://dx.doi.org/10.1023/A:1020243429353

Kangas, K., Seitamaa-Hakkarainen, P. \& Hakkarainen, K. 2011. Design expert's participation in elementary students' collaborative design process. International Journal of Technology and Design Education, 12, 1-18.

Kuhn, T. 1996. The structure of scientific revolutions (3rd ed.). Chicago: University of Chicago Press. http://dx.doi.org/10.7208/chicago/9780226458106.001.0001

Lewis, T. 2006. Design and inquiry: Bases for an accommodation between science and technology education in the curriculum. Journal of Research in Science Teaching, 43(3), 255-281. http://dx.doi.org/10.1002/tea.20111

Lewis, T. 2009. Creativity: A framework for the design/problem solving discourse in technology education. Journal of Technology Education, 17(1), 36-53.

Mabaso, B. 2014. ACE technology lecturers' and in-service teachers' understanding of the design process and its enactment in their pedagogical practice. Unpublished Master's dissertation. Durban: University of KwaZulu-Natal. 
Maptose, T. 2014. An emancipation framework for technology education teachers: An action research study. International Journal of Technology Design Education, 24(2), 1-15. http:// dx.doi.org/10.1007/s10798-014-9275-y

Mawson, B. 2003. Beyond 'the design process': An alternative pedagogy for technology education. International Journal of Technology and Design Education, 13, 117-128. http:// dx.doi.org/10.1023/A:1024186814591

Maxwell, A. 1998. Designing a qualitative study. In L. Bickman \& D.J. Roger (Eds.). Handbook of applied social research methods. Thousand Oaks, CA: Sage Publications. pp. 69-100.

Ohemeng-Appiah, F. 2014. Teaching the design process in the grade 9 technology class: A case study of Chatsworth West ward. Unpublished Master's dissertation. Durban: University of KwaZulu-Natal.

Pool, J., Reitsma, R. \& Mentz, E. 2013. An evaluation of technology teacher training in South Africa: Shortcomings and recommendations. International Journal of Technolgy Design Education, 23, 455-472. http://dx.doi.org/10.1007/s10798-011-9198-9

Pudi, T.I. 2007. Understanding technology education from a South African perspective. Pretoria: Van Schaik.

Rowel, P.M. 2004. Developing technological stance: Children's learning in technology education. International Journal of Technology and Design Education, 14, 45-59. http://dx.doi. org/10.1023/B:ITDE.0000007362.21793.88

Shulman, L.S. 1986. Those who understand: Knowledge growth in teaching. Educational Researcher, 15(2), 1-14. http://dx.doi.org/10.3102/0013189X015002004

Tholo, J.A.T., Monobe, R.J. \& Lumadi, M.W. 2011. What do boys and girls think about technology? US-China Education Review, USA, 8(12), 15-25.

Vandeleur, S., Ankiewicz, P., Swardt, A. \& Gross, E. 2001. Indicators of creativity in the technology class: A case study. South African Journal of Education, 21(4), 268-272.

Wakefield, J.F. 1992. Creative thinking: Problem solving skills and the arts orientation. New Jersey: Ablex.

Wenglinsky, H. 2002. The link between teacher classroom practices and student academic performance. Education Policy Analysis Archives, 10(12), 12-28. http://dx.doi.org/10.14507/ epaa.v10n12.2002

Williams, P.J. 2000. Design: The only methodology? Journal of Technology Education, 11(2), 48-60. http://dx.doi.org/10.21061/jte.v11i2.a.4 